\title{
Confirmed Beliefs or False Assumptions? A Study of Home Stay Experiences in the French Study Abroad Context
}

\author{
Wenhao Diao
}

Carnegie Mellon University

\section{Barbara Freed}

Carnegie Mellon University

\section{Leigh Smith}

Institute for American Universities, France

\section{Introduction}

"French was spoken about 95\% of the time among me and my host family (English only in instances when absolutely couldn't understand each other). My host mother spoke clearly and had a lot of patience with us." (67)

"I imagined that my host family would speak only in French ... I was surprised at how much English they spoke." (01)

"I was pleasantly surprised because my host mother is a genuinely nice, outgoing and helpful woman. We spent the first 3 days together and were both quick to adapt to our different \& similar ways of life." (02) "My arrival was nothing that I expected. I was alone in the apartment the 1st couple of days. My host family did not make dinner or offer breakfast until Monday. I was disappointed and very upset". (03)

These statements, made by students who lived with French host families during a 2008 study abroad (SA) experience, capture the dramatic extremes, which characterize student home stay (HS) experiences. ${ }^{1}$ They represent, as well, the controversy that has arisen in the field, as to the power of positive HS experiences to enhance student language learning and the disappointment associated with experiences that do not fulfill these expectations. The purpose of the research described in this article is to help clarify the extent to which either 
prior assumptions, or recent criticism which casts doubt on these assumptions, may have been exaggerated or, if indeed, there is a balance between the two.

The past 20 years have witnessed enormous growth in a diverse array of studies which explore the linguistic impact of SA experiences. During this period a multitude of research projects have investigated SLA/L2 learning in $\mathrm{SA}$, in a number of different languages (Russian, Japanese, French, Spanish, English), utilizing diverse analytic methodologies, addressing different skill modalities, all from various perspectives. While a number of research projects completed before 1990 used standardized tests to confirm the linguistic benefits of study abroad experiences (Carroll, 1967), many studies of the early 1990s measured gain by using the global scores of the ACTFL Oral Proficiency Test (OPI). These included, among others, work in Russian by Brecht and his colleagues (1995), in French by Magnan (1986). Subsequently, scholars recognized the limitations of results based solely on wholistic test scores and emphasized the need to examine precise areas of language growth for SA students. Such studies, as cited below, have focused on gains in oral fluency, syntax, vocabulary, phonology, sociolinguistic and pragmatic usage, and communicative strategies.

As the field matured, researchers continued to compare language gain in $\mathrm{SA}$ versus At Home (AH) but also expanded their perspective by beginning to examine the very nature of the immersion experience itself. Research of this type has explored more closely the kinds of opportunities students have for interacting with native speaker (NS) interlocutors and the qualities of such interactions, qualities of the HS experience, student beliefs, attitudes and evaluations and how these affected learning. (Interested readers may review the literature on students' participation in communities of practice: Dings, 2007; Ishita, 2009, and their language socialization process in the SA setting: Cook, 2008.) What has emerged from what might be called the second generation of SA research is the questioning of some of the most long-standing beliefs about the SA experience itself. In brief, doubt has been cast on a number of prevalent, if sometimes undocumented, assumptions associated with living and learning abroad. These include:

1. Linguistic development benefits from L2 learning in the SA context. In fact, research has demonstrated that improvement is not consistent in all areas of linguistic growth. For example, oral fluency tends to exceed growth in grammar, lexical development and possibly phonology (e.g. Collentine, 2004; Diaz-Campos, 2004; Freed, 1995; Milton \& Meara, 1995; Towell, Hawkins, \& Bazergui 1996; Segalowitz \& Freed, 2004). Sociolinguistic and communicative areas of language learning also benefit from SA. (e.g. Barron, 2006; Cohen \& Shively, 2007; Kinginger, 2008; Lafford, 1995; 2004; Regan, 
1995; 1998; Regan, Howard, \& Lemée, 2009; Shively, 2010).

2. The belief that the amount and frequency of contact that students have with NS will increase their language gain. Despite this persistent belief, it has not been possible to establish a direct or linear correlation between amount of contact and improved language use (Freed, Segalowitz, \& Dewey, 2004; Segalowitz \& Freed, 2004; Taguchi, 2008).

3. $S A$ assures immersion experiences for students. Recent publications have demonstrated that the SA experience is sometimes far less rich and more complex than once believed. Many students have fewer opportunities to use the target language, are not always well received by the NS community and make use of their L1 more frequently than previously assumed. Moreover, students do not always report positive experiences (e.g. Isabelli-Garcia, 2006; Wilkinson, 1998a). At the same time individual psychological traits (attitude, personality) and social identities (race, gender, class) affect learning in the SA context to an even greater extent than they do the regular classroom at home. (Iino, 2006; Kinginger, 2004; 2008; Kinginger \& Blattner, 2008; Pellegrino, 2005)

4. HS is the richest and most important source of L2 learning for SA students. Perhaps most surprising of all the recent challenges to traditional beliefs has been the doubt cast upon the presumed benefits and positive experiences in the HS setting. (Frank, 1997; Rivers, 1998; Wilkinson, 1998a; 1998b; 2002)

It is the last of these areas that motivates the present study. In brief, our goal was to design a study that collected robust data and explored, in greater depth, specific aspects of the HS experience, the attitudes of student participants in these settings and how these feelings and attitudes change in the course of a semester, for individuals and for a collective group. We believed that knowledge obtained from such a study would shed light upon the accuracy of long held but often anecdotal assumptions and the recent challenge to those beliefs.

\section{Literature Review}

The studies we review here relate specifically to student HS experiences while abroad. It goes beyond the scope of this article to conduct a full review of the literature on language learning in a SA context. (The interested reader is referred to Kinginger, 2009 for such a review and discussion.) The majority of prior studies have focused on the experiences of a small number of students, usually as case studies of 1-10 students. Such studies address the thoughts and feelings of a limited number of individual participants over a specified period of time (e.g. Kinginger 2004; 2008; Pellegrino, 2005; Wilkinson, 1998a; $1998 \mathrm{~b})$. The few larger projects report on participants' experiences once, or 
at most, twice in the course of a semester (e.g. Knight \& Schmidt-Rinehardt, 2010; Schmidt-Rinehardt \& Knight, 2004). These studies utilize primarily qualitative approaches or quantitative analyses.

Wilkinson's (1998) comparison of 2 female sojourners living with French host families utilized interview data which established the highly divergent experiences of her 2 participants. While both started with similar backgrounds and proficiency in French, only 1 of the 2 successfully engaged in communicating with her host family. The other became isolated and eventually withdrew from L2 learning. This study ended by problematizing the limited interactions between SA participants and their host families and negative perceptions of the target culture/language some students developed in response to these interactions. Kinginger and Blattner's (2007) case study of 3 French L2 learners' experiences again revealed divergent student experiences. One participant reported limited interactions with her host family while the other 2 managed to have engaging conversations with the host family.

The findings from Franks' (1997) qualitative study resonated with certain aspects of Wilkinson's claim. His nine participants, who lived with Russian host families, reported insufficient, repetitive and overly predictable contact between the families and SA students. By contrast, Pellegrino's (2005) diary study focused primarily on six SA students, also in Russia, suggested that patterned interactions with host families might provide feelings of security and improved self-esteem. In terms of time spent watching TV, one participant described it positively, as an activity that allowed her to bring "conversation topics to the kukhnya (kitchen)" (p. 141). Nonetheless, the experiences of Pellegrino's students were not exclusively positive. Some expressed a sense of alienation while living with Russian families, feeling that they were treated as less competent interlocutors. One student, an African American, felt she was treated "like a doll" (p.65) by her host sister. Two others reported emotional as well as physical threats based on the host family's son playing of a game of "shoot the Americans" (p.48).

Feelings of alienation and exclusion were also reported in Iino's (2006) conversation analyses on three excerpts of tape-recorded interactions between American college students and their Japanese host families. His analyses revealed that Japanese NSs tended to perceive the idiosyncratic speech of their non-Asian learners' guests as "cute" (p.166). As a consequence students reported that they received little corrective linguistic feedback. Kinginger's (2008) case studies of six American college students in France, also pointed to the role of national identities and ideological differences in interpretations of national and political topics that potentially become sources of conflict between SA students and their host families. In the case of her students it was 
the discourse of the "Iraq War" that led to some of the participants' divergent HS experiences.

Other recent work has examined the relationship between language gain and language use in the HS setting. Rivers (1998) compared 285 students living with Russian host families with 2529 in the dormitory and found that HS was a negative predictor for L2 gains in speaking and had no effect on listening. Dewey (in press) compares the linguistic impact of different residential arrangements on different categories of students: "traditional" /SA classroom study students living with host families, "service learning" students, also living with host families, and non-SA students living in $\mathrm{AH}$ foreign language housing. Although the two SA groups reported significantly more time using L2 than the FL housing group, the 3 groups showed almost no differences in gains in L2 oral skills. Dewey attributed this "counterintuitive" finding of no significant differences between $\mathrm{SA}$ and $\mathrm{AH}$ groups, to the possible superficial level of interaction between SA students and their host families, compared to the engaging conversations between students in FL housing with their Spanish roommates. Both Rivers (1998) and Matrtnsen et al (2010) used quantitative measurements to compare different residential groups, and both concluded by casting doubt on the quality of interaction within the HS setting. However, each of the studies had inherent weaknesses. The samples presented by Rivers (1998) were selected from time periods between 1994-96 and were compared to groups living in student dormitories from the 1970s to 1996. Martensin etal's (2010), the sample size is small (19 in "traditional" group, 13 in "service learning" group, and 16 non-SA students in L2 houses) and the SA period short (7-week).

Schmidt-Rinehart and Knight (2004) examined student evaluations of the HS experience as a source of cultural and linguistic learning. Their data was gathered utilizing a survey instrument administered on a single occasion to 90 students, (as well as 24 host families) in 4 different sites (in Spain and Mexico), over a 2-year period. The results showed that, overall, students evaluated the HS setting as a positive cultural experience, providing a comfortable place for interaction that helped promote their understanding cultural practice. In terms of L2 use however, the participants did not report spending large amounts of time interacting with their host families. The authors' interviews, with 40 participants randomly selected from the total population, showed that many reported being excluded from family activities. Interestingly, the host families' responses revealed that they thought the students were "busy and just 'passing through' on their way to other activities" (p. 261). In their more recent study of 118 participants in Mexico and Spain (Knight \& SchmidtRinehart, 2010), the researchers incorporated tasks intended to help students 
initiate and enhance interactions with host families. The results though were that the group who was assigned these asks suffered a high attrition rate, and did not spend significantly more time speaking with their host families than did the control group. On a disappointing note, the authors concluded "there is a gap between what they (the students) want to do and what they do" (p. 76). Qualitative analyses revealed that some participants found that the topics in the assigned interviews were lacking interest and often turned their family conversations into "interviews." As the authors acknowledge, having a single measure at the end of the semester may fail to fully capture students' beliefs and attitudes as they change over time.

In summary, most of the projects reported above were based primarily on small case studies. Though the stories of these individuals were compelling and unquestionable, the extent to which the problems they identified are representative of the full HS experience of a larger population remains unstudied. The larger studies (Rivers, 1998; Martinsen et al, 2010; Knight \& Schmidt-Rinehardt, 2010; Schmidt-Rinehart \& Knight, 2004) had design limitations as described above. Nonetheless, as a group they offer some provocative thoughts regarding the HS living experience. Their findings suggest that some students in the HS setting do not use the target language in as many situations as would be assumed, as much as they would wish, nor as much as was once believed. Moreover, based on the studies that present the perspectives of a few focal participants, HS experiences are not uniformly positive (Kinginger \& Blattner, 2008; Iino, 2006; Pellegrino, 2005; Wilkinson, 1998a). The divergence of student experiences, as portrayed above leads us to question simultaneously pre-existing assumptions about the richness of the HS experience as well as the more negative interpretations of these experiences that have recently been reported.

It is the juxtaposition of these positions that convinced us of the need to organize a project that would provide for robust data, collected from one SA site, from a relatively large population, over multiple points in a full semester and analyzed from different perspectives. We thus established 2 general research categories, each including multiple questions. We anticipated that our results would enrich interpretations of the many nuanced levels of understanding the SA home stay experience. The categories and questions were as follows:

1. Interaction in the home stay setting:

- With whom do students interact the most during their time abroad?

- In the HS setting, whom did they interact with the most?

- Where did the interactions take place?

- In what languages did their interactions take place?

- What did they talk about? 
- Are students' expectations met?

- Are their feelings (distinct from expectations) generally positive or generally negative? Do these feelings change over time?

2. Using and learning French in the home stay setting:

- Whom did students identify as the primary source of their learning?

- How did students describe the positive linguistic benefits of the HS experiences?

- What did the students describe as the negative aspects of their HS language learning experience?

\section{Methodology}

\section{Institution and Participants}

In the fall of 2008, 102 undergraduate students were enrolled at the Aix Center of the Institute for American Universities (IAU) in Aix-en-Provence France. Aix is a culturally rich Provencal city with diverse educational institutions, including the Université d'Aix Marseille and several centers for foreign students, both American and European. IAU is an independent, accredited but non degree-granting institution that accepts students, with and without prior study in French, from a cross-section of American colleges and universities. All students are required to study French and those who are sufficiently advanced may take courses at the Université d'Aix-Marseille.

Of the 102 enrolled students, 32 were eventually eliminated: either because they were unwilling to participate in the project, did not live with a HS family or failed to complete all of the required questionnaires. The final population of 70 students included 56 female and 14 males, between the ages of 19-25. The first language of the majority of students was English but 2 were NS of Spanish, 1 of Vietnamese, 1 of French and 1 of Turkish. Prior to their arrival in Aix, 15 students had taken more than 2 years of college French, 37 had 1-2 years of college French, 6 had had less than a full year of undergraduate French while 12 students had no prior study of French. Students' majors varied as follows: 17 in the Social Sciences, 17 in Economics, 10 in the Sciences, 9 in French, 8 in International Studies, 5 in Art (art history/fine arts/theater arts) and 4 in Miscellaneous disciplines (e.g. digital media studies, strategic communication).

\section{Instruments}

Two distinct data collection instruments were utilized. The first was the Language Contact Profile (LCP) (Freed et al, 2004). The LCP includes 2 forms 
which may be adapted to specific needs of scholars conducting research in language learning and SA. The Pre-version is a comprehensive questionnaire on general demographic issues that affect language learning (L1, home language, amount of prior language, etc.) The Post- version includes approximately 10 questions which focus specifically on student experiences while abroad and which lend themselves to quantitative and qualitative analysis. These questions inquire about whom students interacted, the amount of time spent with different types of interlocutors, the language(s) they used during these interactions, etc.

In addition, 12 short weekly questionnaires, designed by the project researchers, were used for data collection. These open-ended questionnaires asked about students' interactions with their families, their general expectations and feelings as well as those related to French language learning. Each questionnaire included 4-6 questions, which could be answered in approximately 10 minutes. The questionnaires were intended to serve as proxy journals and permitted students to express confidential positive and negative thoughts about their HS experiences. While 12 questionnaires were utilized, not all of the questionnaires, nor all of the questions on each of the questionnaires, are being reported in this article. Selected for this report are those that deal exclusively with student HS interactions, student expectations, feelings and evaluations with respect to their language learning experiences with their French families

\section{Procedure}

This project was endorsed by IAU but with no requirement that students participate in the project. The on-site project coordinator described the project to students at the beginning of the semester and asked those who volunteered to sign consent forms. In compensation for completing all aspects of the study, volunteers were entered into a lottery, which provided a round-trip ticket to France.

The pre and post LCPs were distributed in large group sessions at the beginning and end of the semester. The weekly questionnaires were distributed to volunteers during the final 10 minutes of each week's last class session. Teachers collected the questionnaires and immediately gave them to the coordinator.

\section{Analysis}

Given the 2 major goals of our study, our analyses focused on these areas at multiple points during their 13 weeks in France. The number of returned questionnaires ranged from 49-70 per week. Thus, the total numbers reported 
for various questionnaires differs from week to the next. In addition, students were occasionally given the option of responding to multiple categories on a particular question, thus the total number sometimes exceeds the total number of participants. No effort was made to pre-determine the points at which student reports would be analyzed. Rather, we considered student expressions as they emerged spontaneously from their responses at various times throughout the semester.

The breadth of our questions, along with the variety of instruments utilized, offered the opportunity to use 4 different analytic approaches for data analysis:

1. The first approach was purely numerical. ${ }^{2}$ It was used to calculate the number of hours per day students reported interacting with various interlocutors. To test for statistical significance, we ran a t-test to compare the number of reported hours for each of the two groups with the highest reported hours (family and service personnel.) By elimination, all other groups were measured against these.

2. The second approach combined quantitative and qualitative analyses. ${ }^{3}$ This analysis involved 3 consecutive steps: 1) qualitatively coding participants' responses by extracting terms directly from their written data as they recurred across different participants and then categorizing them; 2) triangulating the participants' responses through similar questions across different questionnaires; 3) quantitatively calculating the frequency of each category of responses.

Following Ritchie and Lewis' (2003; p. 210-211) emphasis on the need to systematically apply the same code across the full data set, we synthesized students' terminologies to establish consistent codes. For example, we chose the word children as the label for the various terms participants used to refer to children in their HS families: "brother", "sister", "kids of our age" and "siblings". We also looked at all 70 participant's responses to similar questions, across different questionnaires, for triangulation. ${ }^{4}$ After certain topics recurred, they were coded and rechecked to ensure both inclusiveness and exhaustiveness.

3. The third approach again involved quantitative and qualitative analysis. However, unlike category two above, which did not predetermine categories, we began by utilizing pre-determined categories in the qualitative coding analysis. We used this type of analysis to explore students' expectations and feelings. We began by separating two overlapping but quite distinct categories: "expectations" and "feelings." "Expectations and feelings were coded from all of the questionnaires in which these categories emerged.

Given the large amount of data for feelings we adopted appraisal analysis (Martin \& Rose, 2003) as a tool and pre-assigned "positive" and "negative" categories and coded each of the participants' weekly questionnaires accordingly. 
If the response used students' words and/or phrases such as engaging, caring, encouraging, fun, proud, fantastic, comfort), it was coded as "positive." If it used students' words and/or phrases that indicated negative feelings (homesick, boring, isolated, frustration, disappointment, isolation and fear), it was coded as "negative." Sometimes participants responded with both negative and positive phrases and these responses were therefore coded as "mixed." On rare occasions students' responses gave no hint of their feelings, positive or negative. These were coded as "No Feelings." We then quantitatively calculated the percentages of participants within each of these categories. Finally, we added a third step in which we analyzed the evolution of feelings both qualitatively by categorizing them and quantitatively through percentages of the participants within each category. A similar approach was adopted to code and analyze expectations.

4. The fourth approach included four steps of analysis: 1) qualitative coding and categorizing; 2) quantitative calculation; 3) qualitative coding within each category; 4) quantitative ranking. ${ }^{6}$

The qualitative coding and categorizing procedure identified a number of student-expressed themes (e.g. extension of the classroom, too much English) with respect to language learning with their HS families. These evaluations were organized into pre-determined categories of positive, negative or mixed. In so doing we were able to understand which factors constituted, from the participants' perspectives, the benefits and limitations of language learning in the HS setting. This approach permitted us to provide a richer description by identifying themes that recur from week to week.

\section{Results}

Our results are organized according to our two research categories, and in response to the questions within each of these categories.

\section{Interaction in the HS setting}

The following story emerges from our results. We learn first that students (based on their own calculations) spent significantly more time interacting with their French families than with any other group in the local community. Students described spending an average of almost 16 hours per week with their families (see Table 1), as compared to other social encounters, including time with friends (3.83 hours/week), classmates (4.91 hours/week), strangers (5.46 hours/week) and service personnel (6.54 hours/week) $(p<0.05)$ (see Table 1).

Within the family setting more than half of our students identified the HS "mother" as the family member with whom students had the most contact. Forty-three of our total 70 participants lived in either families with a mother and children (15 students), families with both parents but no children 
(10 students), or families with two parents plus children (18 students). For that group as a whole, $55.81 \%$ of the participants identified the mother as the family member with whom students interacted the most (see Table 2). Another twenty-seven of the total 70 participants lived in "families" with only a single-mother (no spouse, no children). These students thus had essentially no choice other than their host mother. Therefore, we have not included those students in the results with respect to which HS family member students interacted with the most. Had we included this misleading number, we would have reported that $71.42 \%$ of students reported having the most contact with their for host mother.

French was the primary language of interaction for two-thirds of our students (see Table 3). Forty-four of our 70 students reported consistently interacting in French with members of their HS family. Another twentythree students (32.86\%) claimed to speak a mixture of English and French. One student identified French and Arabic as their major languages of communication. Thus for the vast majority of our program participants, French was used, at the least, as one of the languages if not the only one in the HS setting. Two participants reported English as the sole language used with their host families.

Almost all of our students identified the family "dinner table" as the primary site of interaction with their host family, followed by the kitchen, living room, bedroom, or as they vaguely stated "in passing" (see Table 4). For some students, the dining room was the only space in which students had regular and sustained interaction with their families, since, as one said "we only see each other at dinner," or "our dinners are over an hour \& we talk a lot." Others, described going to the kitchen after returning from school to "see if I can help with dinner," and therefore "most of interaction is @ dinner table or sometimes in the kitchen helping her to prepare meals." Sometimes, concurrent with or prior to sitting down to dinner, students, with their families, would watch or listen to the news: "conversations at dinner are usually dependent on what is on the News since we watch the News at dinner", or "in the living room watching some news".

Topics of discussion were clearly oriented toward the major issues on the news. For example, as shown in Table 5, "election" (i.e. the US 2008 presidential election) emerged as the most commonly discussed topic (reported by $61.76 \%$ ) followed by food, family and politics (42.65\% each.)

While concrete information responding to questions of who, what, where and when is central to knowing some of what transpires in the HS setting, understanding students' expectations and feelings about these experiences is even more important. Students were asked on three occasions (the end of 
the first, $7^{\text {th }}$ and last week of the program) if their expectations had been met. (Note \# 5 discusses the distinctions between expectations and feelings.)

Three distinct categories emerged from our analysis: Yes (clear affirmation), No (clear negativity) and Mixed (Yes/No). Table 6 reveals the extent to which student expectations varied over time.

At the end of the first week, affirmative responses were at an all time high $(60.29 \%)$. By the $7^{\text {th }}$ week that figure had declined to $35.42 \%$. However, by the end of the program the extent to which the group reported a clear "Yes" to the meeting of their expectations had rebounded to $57.97 \%$.

The voices of our students best express their thoughts at each of these points. Responses at the end of the first week were the simplest and clearest. Students hoped for and expected a warm welcome upon arrival and the majority described welcomes that were "a pleasant surprise," or "relief" at discovering that the family spoke both French and English.

- They were better than I expected - my host mom was so friendly and warm and I felt as though I was at home. (0004)

- Things were better than expected b/c my host mom speaks very good english so its easier to get to know each other. (8379).

Contrary to, the unequivocal "Yes" responses, students whose initial expectations went unfulfilled responded negatively, saying things such as:

- I lost my bag. It was hard to communicate with my parents because only one spoke a little English (4168)

- My arrival in Aix was not as smooth as expected and my greeting was not either. The first few days was rough, due to culture shock, time difference, language barrier, etc. (0005)

The responses of a small number of students were clearly ambivalent, indicating expectations met only in part (Mixed):

- My greeting was good - not exactly what I had expected - maybe because I was tired \& had 24 hours in an airport. (7948)

- I did not expect an apartment without air conditioning and 5 people. However, they greeted me very kindly and I'm getting used to the lifestyle. (0008)

As depicted in Table 6, things changed over time. Seven weeks later, students' expectations gradually evolved into being "taken as part of the family:"

- I have a comfortable place to stay. I live with a family who is interested in interacting with me and helping me improve my French. (9040)

- My host mom completely reminds me of my grandma and she completely makes me feel at home. (447)

Reactions of some, however, were "mixed" as things did not progress exactly as 
they had anticipated:

- I enjoy the people that I stay with, however, I don't always feel at home. (8163)

- It exceeded my expectations except that we usually only interact at the dinner table. (8170)

For a small percentage $(6.26 \%)$ there was utter disappointment:

- It really hasn't met my expectations because I thought I would be taken in as family. Sometimes I feel unwanted, like my host mom doesn't like it when I come home or stay in. (5286)

By the end of the program, a week after classes ended, participants reevaluated their expectations, offering again, positive, mixed and negative evaluations. Positive evaluations were often related to using and learning of French:

- My host mom speaks only french to me and she constantly talks about France. (5732)

- It was as I expected. I used french as much as possible and learned quite bit. (9223)

Retrospectively, others reported partial meeting of their expectations:

- More or less, sometimes more, sometimes less. (4177)

- I still believe that my french improved to some extent but not to its full potential. (9350)

For a few, expectations of regular interactions, learning French and about French and living condition, were unsatisfied:

- Didn't get to spend time w/ family. (5774)

- I didn't learn French or have French food. I was disappointed not having internet. It was very inconvenient. (8379)

These constantly evolving perceptions of expectations reflect Paige et al. (2003) U-shaped curve that captures changing reactions as time progresses (Figure 1). Feelings, as compared to expectations assumed similar, if different patterns, during the 13 weeks of student's time in Aix. (Note \#5 describes difference between expectations and feelings.) In the early weeks, students expressed positive feelings with descriptions of stability, part of the family, interesting. For those whose feelings were negative there were expressions such as lonely, tiring, hard, provocative and weird. As time continued, some students felt they had a comfortable and enjoyable atmosphere at home, while others struggled with feelings of exclusion (feel like a guest) and frustration. By week 7 there were fewer positive feelings, and more mixed feelings than at any time before. By contrast, during week 8 , there were more positive feelings and fewer negative or mixed feelings. Table 7 quantitatively illustrates the fluctuation in feelings. 
As the semester progressed, there was a diminution in expressions of exclusively positive feelings at the same time that negative and mixed feelings increased. Notably, by the end of the semester the number of mixed feelings was at its greatest. Table 8 summarizes the student voices behind mere numerical ratings in Table 7.

\section{Using and Learning French}

The second major component of our story, intimately related to interaction in the HS setting, addresses students' impressions of how HS experiences contributed to their learning of French.

Earlier we reported that students spoke French significantly more with their HS families than with any other category of French speakers. At the end of the semester, students told us more about how they viewed the roles of their HS families in their emerging French language skills. Two final questionnaires (Questionnaire \#12 and post-LCP) were administered during the last two weeks of the program.

Of the 56 students who responded to Questionnaire \#12, a full $66 \%$ (37 students) identified their French families, usually along with another category of native French speakers, as their primary source of language learning. In addition to the HS family, twenty-six students (46.43\%) identified the classroom as a primary source of learning; ten participants (17.86\%) cited French friends as major sources of learning, while nine of them $(16.07 \%)$ reported local exploration, such as go out in the town, stores, bars and clubs, the train station, going out, and the community as sources of French language learning. Since our students could identify more than one source, the total percentage does not add up to 100 .

A week later, in the Post LCP, the majority of students offered positive views of the HS setting's contribution to their language and culture learning. Roughly sixty-four percent (63.77\%) unequivocally evaluated their HS experience as positive in this respect. Eighteen (18) more $(26.09 \%)$ held mixed responses, identifying both positive and negative aspects of language and cultural learning in the HS setting. A small percentage (10.14\%) offered negative responses in this regard.

Overall evaluations (positive and/or negative) of students' linguistic experiences in the HS setting emerged from these two questionnaires.

As described by our students, the positive aspects of their experiences in the HS setting included: 1) French immersion; 2) improvement of aural/oral skills, 3) feelings of comfort and consistency, 4) learning linguistic and sociolinguistic knowledge about French, 5) HS as an extension of classroom, 6) learning of 
both language and culture, 7) being exposed to French media, and 8) having a roommate helps comprehension. Of those who gave negative comments, the themes can be categorized as: 1) interactions are limited, 2) feeling excluded from conversations, 3) the host family speak too much English, 4) imbalance between language and culture learning; 5) having difficulty understanding the host family, 6) having a roommate reduces opportunities to interact with the host family directly, and 7) no learning of either language or culture.

Our students' voices, quoted below, bring to life the meaning of the most prominent positive and negative themes emerged in their responses. Below are some of their positive comments:

\section{1) French immersion:}

- Living with a family was definitely the most helpful. It forced me to speak and listen in French in a way that no classroom experience could have provided. (7792)

- Speaking French with my host family because it forced us to be immersed in it and the only way we could communicate with them was in French. (9755)

\section{2) Aural/Oral Skills:}

- It taught me a lot of commonly used phrases and got me used to listening to French and trying to understand stories. I also got better at expressing myself to my host mom. (8654)

- Conversations at dinner $w /$ my host family. I can totally tell that my listening comprehension has greatly improved! I can understand and add to true conversation all the time. (8437)

\section{3) Comfort/Consistency}

- I learn from all of these opportunities... Family helps slow things down and creates a comfortable learning/speaking environment. (4323)

- My French family was the most consistent place and I have learned much vocab and phrases there. It has also been the place where I have consistently spoken French practically everyday (except Saturdays). (9223)

\section{4) Linguistic/sociolinguistic knowledge}

- My French host mother helped me to learn new expressions that young ppl in France used. (1662)

- I think the richest experience was living with a host family - I learned so many words/phrases, and bits of information from them. (8170)

Negative responses were reported in equally compelling words: 


\section{1) Limited interaction}

- Well, b/c I lived in an apartment underneath the house, I only saw my host parents 1 or 2 hours a night for dinner. The conversation was always rich \& interesting, but limited to once a day. The limited hours of communication were the only problem. (8583)

- It was hard to speak a lot of French w/ them though since I really only saw them at dinner. Since I was at school all day \& they were at work, then after dinner I would do my hw/showerletc so I would be in my room. (6755)

\section{2) Excluded from conversations}

- They spoke way too much alb personal things at dinner and didn't address me, many nights in a row, they did not engage me in interesting conversations. (1720)

- The only thing would be is they spoke really fast and would exclude me from conversation, but I would listen and try to figure out what they were talking about. (4168)

\section{3) Too much English:}

- She spoke a lot of English and if I didn't directly ask what a word was in French she wouldn't help me out...i.e. I'd be in the middle of a French sentence and switched to an English word \& she'd just nod that she understood it... really annoying. (8605)

- The fact that the dad spoke English definitely hindered my language learning b/c had I been forced to speak more French I gladly would have however, his speaking English increased my cultural understanding greatly as we never would have had half the conversations we did had he not spoken English. so it was a trade off. :) (2290)

\section{4) Imbalance between language and culture learning:}

- learned lots about family lifelculture. language learning in the home was inhibited by use of english when conversations became difficult. (4177)

- I was very satisfied with my exposure to French culture, but my exposure to the French language was minimal. (0447)

\section{Discussion}

Our goal in initiating this project was to compare the long held and cherished beliefs traditionally associated with the presumed linguistic and cultural benefits of living with a HS family with some of the contradictions and cautions brought to our attention in the literature of the recent past. Sobered by some of these reports, which via rich case studies have described the 
sometimes disappointing HS experiences of some students, we felt challenged to find a satisfying interpretation to this puzzling contradiction. We believed that conducting a study of a relatively large population, in one research site, collected at on-going moments throughout the semester would yield to a "rich" description based on both quantitative and qualitative analyses. As described above, our findings support both the historically glowing anecdotal reports of scores of SA students regarding the value of their HS experiences, at the same time as they find support for more current disclaimers regarding negative aspects of students' HS experiences that have captured the attention of many in the SA field.

At the macro level, the majority of our students were positive about their HS experiences, large numbers of them expressing, throughout the semester, satisfaction with their HS experiences. They reported spending the most time interacting with host family members. The HS represented one, if not the only major source of French learning. The participants relate their satisfaction with their language and culture learning experiences and the extent to which the home often served as an extension of classroom practices: to the immersionlike environment in which they "were forced" to use French and to the fact that many families provided a sense of comfort and consistency for them.

Within the HS setting, the participants interacted most frequently with the HS mother, usually speaking French but in some families a mixture of French and English. Commonly interaction occurred at the dinner table, as well as in the kitchen and the living room, frequently with the TV/radio on. They discussed a wide range of topics, often those broadcast on TV/ radio that drew international attention (e.g. the 2008 American presidential election), as well as quintessential French subjects such as "food" and "family." In comparison to Kinginger's investigation (2008), in which the "Iraq war" was a salient discourse topic for her SA participants in France in 2003, our participants, five years later, were less concerned with the war than the election. This comparison confirms the "here and now" tendency in the topic selection among SA students. They talked about things that were more temporally, spatially and emotionally relevant at the time of their visit to France.

These conversations not only provided an "opportunity space" in which these newcomers to France could socialize (Cook, 2006), but also constituted a "learning space" for both linguistic and cultural knowledge as revealed in some of their enthusiastic evaluations:

- We talked about immigration in France, feelings towards other societies, the rights and wrongs of human behavior. They've taught me many words, expressions and even little songs. I've eaten rich and an abundant variety of French cuisine. We have discussed misunderstandings b/t cultures and talked 
about love." (8533)

- It helped me to learn everyday language and forced me to practice confidently with my host mother. I learned so much about French attitudes and culture through her. (2170)"

Yet, to conclude that living with a local family is consistently and exclusively a happy experience is a false assumption and an oversimplification. We found in our larger group, a divergence of a different type than that described in the literature. Among our students, rather than merely different experiences from student to student, or for one part of the group as compared to another, we identified patterns of divergence from one moment to the next. This is best explained by considering the factors that contribute to the fluidity of students' expectations and emotional responses - positive and negative - during the course of their time abroad. For example, just before mid-term break, week 7 , there was a decline in student satisfaction. It may have been that the routine of classes and living with a "foreign" family had accumulated to the point that many were eager for a respite, from speaking French and a yearning for travel elsewhere. However, after a week away, they returned to their host families, many of them expressing the feeling of "coming back home," and "better than living in a suitcase," with appreciation for the "comfortable" and "enjoyable" atmosphere with their HS families. This increased (albeit temporarily) the expression of positive feelings at mid-semester (week 8), corresponded with a drop in negative and mixed percentages at the same moment, and after week 8. Intercepting this temporary change, there are two intersecting U-shaped curves which represent qualitative evolutions of feelings.

At the beginning of their time in France, many students felt "welcomed" and "settled" and their host families "friendly." As time continued, some of them established a "comfortable" and "enjoyable" atmosphere at home, while others struggled with feelings of exclusion ("feel like a guest") and frustration. After the mid-term break, some of the participants became "closer" to their host families, and felt "more comfortable," as they became better acquainted with their HS members. However, others began to feel "homesick" and "awkward," finding it "hard to initiate new activities." Perhaps most significantly, though, is that by the end of the semester students appeared to have arrived at a level of seeming objectivity, a point where they were able to express both satisfaction and regrets with respect to their experiences. By the last week of the program, the number of students who articulated mixed feelings was at an all time high. For us, this balanced recognition of good and bad, positive and negative, helps illuminate prior reports, which were unabashedly glowing or frighteningly critical. These reports were largely of individuals, and thus had difficulty capturing the subtlety of fluctuating feelings and the intertwined experiences 
associated with a SA experience.

Similar explanations might be offered to interpret student comments about the use of English. At the outset, many students anticipated that being able to speak English would be an asset in view of their insecurity in using French upon their arrival. As their confidence in French increased so did the displeasure with the continued use of English by some of the families. These negative evaluations might be interpreted within larger social and historical contexts in which their SA experience took place. As applied linguists, we are well aware of the impact of the global spread of English (e.g. Graddol, 2006). This fact surely influenced the day-to-day interactions of some of our students with their French host families. This phenomenon is not unique to $\mathrm{SA}$ in France. Globalization and its consequence of Anglicization has created an ever increasing population of English L2 speakers and learners in many SA destination countries, and has changed greatly the SA experience today from the way it was in the past (Coleman, 2010). These ESL speakers' increasing proficiency in English often makes English a convenient lingua franca between themselves and the overseas Anglophone sojourner. Total immersion in their L2 while abroad is sometimes more illusionary than before.

The finding that there are no simple yes and no answers to students' feelings about HS experiences emphasizes the fluctuation of student attitudes and feelings. It also elucidates the findings of some of the previously reported diary studies. While there were moments when a large percentage of the population was positive, it is clear that the mixed response of "yes and no", sometimes, "and, but..." " no, but..." is representative of the feelings and experiences of many students at different period of time. This understanding is salient to interpretation of student experiences in the HS setting. Indeed, for these young travelers, living with a "new family" is an ongoing process, as "when individuals move across geographical and psychological borders, immersing themselves in new sociocultural environments, ...they enter a period of struggle to reach a balance" (Block, 2007, p.864).

It is also interesting to note that students with different language learning levels may differ in their interpretations of positive and negative language learning experiences. ${ }^{7}$ Consider, for example, that while some higher level students identified the "improvement of communicative skills" as a positive theme, elaborating that this meant "expressing myself", engaging in "conversations lacking in school", and having opportunities for "debating about politics." Lower level students defined "improvement of communicative skills" as being better able to "hear" and "understand." This distinction between students at different levels was apparent as well in explanations about "too much English being spoken at home". Lower levels students qualified 
their negative comments about the use of English, by adding "English made cultural discussions easier" and "increased my cultural understandings greatly." Higher level students, by comparison, had nothing at all positive to say about the use of English in the HS setting.

Disappointment with the HS experience is sometimes evident at the microlevel with individual experiences, particularly their sense of exclusion, limited interactions with host families, and unbalanced language and culture learning. The occasional sense of exclusion among SA students (reported previously by Kinginger, 2004; 2008; Iino, 2006; Pellegrino, 2005), is echoed by some of our students. As newcomers to the HS setting, these transient residents do not always become part of the family and totally immersed in French language and culture learning. "We interact in passing" sadly exemplifies the theme of "limited interaction" expressed by some of our subjects. For these students, interaction is characterized as brief, and often superficial. As such, it reflects questions posed by Frank (1997) and Wilkinson (2002) as to the quality of interaction within the HS setting.

It may be further exemplified by the extent to which individual and thus group student evaluations are combination of their imaginations and their real life experiences while abroad. Those who expressed disillusionment at not having been served "real French food" or not having attained the "fluency" they had expected could not help but be disappointed.

Our results, based on the detailed analysis of weekly reports by seventysome students over a period of thirteen weeks provide a nuanced and balanced image of the experiences and evaluations of a group of American students studying in France for a semester. Had we explored their thoughts and reactions at only one point in time, or had limited them to a small group of students, our conclusions might have been skewed one way or another.

\section{Conclusion}

Our study brings documentation to the long-standing assumption, supported by decades of anecdotal reports and empirical findings that for many students living with a home stay family is the very heart of the SA experience living and is an overwhelmingly valuable experience for both linguistic and cultural development. At the same time, our results demonstrate that this is a far more subtle and nuanced experience than previously believed and not as the simple as the unexamined belief led us to believe. As other recent studies have suggested, the family home stay experience is not a positive experience for all students, nor is it always a positive experience for any one student. Living and studying abroad, as living and studying at home, but even more so, is fraught with challenges and adjustments. Feelings are transient 
as are interpretations of experiences as they evolve over time. Analyzing the interactions and evaluations of a single, and relatively large, group of students, at multiple points in time has provided an opportunity to understand the ebb and flow of student reactions and to offer a balanced view of the study abroad home stay experience.

As language learning in the SA context has matured as a recognized sub-field of applied linguistics, the pendulum has swung from a pronounced focus on the "product" of learning to the process of learning itself, more to an understanding of what transpires in the SA context and how that process may affect the outcome of the experience. There remains more to learn about the two sets of participants in the SA experience - the student-travelers and the native speaker resident community, their dialogic process, what each brings to the experience and how that affects the other. As we continue to fine-tune our insights into the richness of this interaction, we will continue to learn more about the nature of the linguistic demands placed on students and the difference in their responses to these demands that result in enhanced or diminished language and cultural learning. It is this deepened understanding of the HS experience that permits us to think beyond the once deceptively simple belief that going abroad guarantees enhanced language learning.

\section{Acknowledgements}

We wish to express our appreciation to the Institute for American Universities in Aix-en-Provence France, which provided the site for our research and encouraged all students enrolled during the fall 2009 academic semester to participate in our project. Special thanks are due to all of the students who shared their time and thoughts with us throughout the semester, carefully completing our questionnaires and Language Contact Profile. We also express gratitude to the many teachers who willingly provided a portion of class time to students to complete their questionnaires. Without their generous contribution of time and interest our data and results would never have been as rich.

\section{Notes}

${ }^{1}$ All the students who participated in our study were assigned a randomized code number. These code numbers are used to protect student identity. They appear in parentheses next to any statement made by a participant. No student comment has been corrected for grammar, spelling, punctuation, or in any other way.

${ }^{2}$ This was used to analyze portions of the LCP's and the first question in Research Category I/Interaction (who students interact with the most during 
their time abroad) categories of data which required purely numerical analysis. This approach was used to answer certain questions in Research Category I (questions about interaction: with whom, in what language, where, and about what) and Research Category II /Using and Learning French (question on sources of learning French).For instance, in coding the topics of interaction in HS, we looked primarily at their responses to Questionnaire 4, and then triangulated them with Questionnaire 2. In so doing, we obtained data which established recurrences of patterns of interactions for as many participants as possible, considering that not all participants returned their questionnaires every week.

Expectations referred to both "pre-program" expectations (notions, or imagined ideas that students had about what their experiences might be) prior to arriving in France and "on-going" expectations, based on experiences they were having and how they continued to imagine/or expect the interactions to continue. By contrast, "feelings" were more subtle and nuanced. They included often fleeting and frequently temporary emotional responses that represented students' reactions to events, activities and interactions within the HS setting. Obviously there was some overlap between these two categories but for the most part, expectations were clearly distinguished from the positive and negative emotional reactions that students expressed in the HS setting. In our analyses and results, expectations reported during the first week of the program referred to expectations students had prior to coming to France. At later points it referred to their evolving notions of how the experience should continue to develop. This approach was used for the last two questions in the Research Category II (positive linguistic benefits and negative aspects of learning and using French).

To determine if there was any possible relationship between students' level of French and positive and negative comments they made about language learning in the HS setting, we divided the students into Low and High Groups. The "Low" group had either no prior study of French or less than one year of college level French. The "High" group had one or more years of college French instruction.

\section{References}

Barron, A. (2006). Learning to say 'you' in German: The acquisition of sociolinguistic competence in a study abroad context. In M. A. Dufon and E. Churchill (eds.). Language Learner in Study Abroad Contexts. 5990. Clevedon UK: Multilingual Matters. 
Block, D. (2007). The rise of identity in SLA research, post Firth and Wagner (1997). The Modern Language Journal, 91 (Focus Issue), 863-876.

Brecht, R., Davidson, D., \& Ginsberg, R. (1995). Predicting and Measuring Language Gains in Study Abroad Settings. In B. F. Freed (Ed.), Second language acquisition in a study abroad context (pp. 37-66). Philadelphia, PA: John Benjamins.

Carroll, J. (1967). Foreign language proficiency levels attained by language majors near graduation from college. Foreign Language Annals, 1, 131151.

Cohen, A. D., \& Shively, R. L. (2007). Acquisition of requests and apologies in Spanish and French: Impact of study abroad and strategy-building intervention. Modern Language Journal, 91, 189-212.

Coleman, J. (2010, March). Research whole people and whole lives. In C. Kinginger (Chair), The social turn of study abroad research. Invited colloquium at the meeting of American Association for Applied Linguistics, Atlanta, GA.

Collentine, J. (2004). The effects of learning contexts on morphosyntactic and lexical development. Studies in Second Language Acquistion, 26, 227-248.

Collentine, J., \& Freed, B. F. (2004). Learning context and its effects on second language acquisition. Studies in Second Language Acquisition, 26, 153-171.

Cook, H. M. (2006). Joint construction of folk beliefs by JFL learners and Japanese host families. In M. DuFon and E. Churchill (Eds.). Language learners in study abroad contexts (pp. 120-150). Clevedon, UK: Multilingual Matters.

Cook, H. M. (2008). Socializing identities through speech style: Learners of Japanese as a foreign language. Clevedon, UK: Multilingual Matters.

Diaz-Campos, M. (2004). Context of learning in the acquisition of Spanish second language phonology. Studies in Second Language Acquisition, 26, 249-273.

Dings, A. (2007). Developing interactional competence in a second language: A case study of a Spanish language learner. (Unpublished doctoral dissertation). University of Texas, Austin.

Frank, V. (1997) Potential Negative Effects of Homestays, Paper presented at The Middle Atlantic Conference of the American Association for the Advancement of Slavic Studies, Albany, NY, 22 March 1997.

Freed, B. F. (1995). What makes us think that students who study abroad become fluent? In B. F. Freed (Ed.). Second Language Acquisition in a Study Abroad Context (pp. 123-148). Philadelphia, PA: John Benjamins. 
Freed, B. F., Dewey, D., Segalowitz, N., \& Halter, R. (2004). The language contact profile. Studies in Second Language Acquisition, 26, 349-356.

Freed, B. F., Segalowitz, N., \& Dewey, D. (2004). Context of learning and second language fluency in French: comparing regular classroom, study abroad and intensive domestic immersion programs. Studies in Second Language Acquisition, 26, 275-301.

Graddol, D. (2006). English next. Available from http://www.britishcouncil. org/learning-research-englishnext.htm

Iino, M. (2006). Norms of interaction in a Japanese homestay setting: Toward two-way flow of linguistic and cultural resources. In M. Dufon and E. Churchill (Eds.) Language learners in study abroad contexts (pp. 151-74). Clevedon, UK: Multilingual Matters.

Isabelli-Garcia, C. L. (2006). Study abroad social networks, motivation and attitudes: Implications for SLA. In M. Dufon and E. Churchill (Eds.) Language learners in study abroad contexts (pp. 151-173). Clevedon, UK: Multilingual Matters.

Ishita, M. (2009). Development of interactional competence: Changes in the use of ne. In H. Nguyen and G. Kasper (Eds.), Talk-in-interaction: Multilingual perspectives (pp. 351-385). Honolulu, HI: University of Hawai'i.

Kinginger, C. (2004). Alice doesn't live here any more: Foreign language learning and identity reconstruction. In A. Pavlenko and A. Blackledge (Eds.). Negotiations of identities in multilingual contexts (pp. 219-242). Clevedon, UK: Multilingual Matters.

Kinginger, C. (2008). Language learning in study abroad: Case histories of Americans in France. The Modern Language Journal, 92. Monograph.

Kinginger, C. (2009). Language learning and study abroad: A critical reading of research. New York, NY: Palgrave Macmillan.

Kinginger, C., \& Blattner, G. (2008). Development of sociolinguistic awareness in study abroad. In L. Ortega \& Byrnes, H. (Eds.), Longitudinal studies and advanced L2 capacities (pp. 223-246). London, UK: Routledge.

Knight, S. M., \& Schmidt-Rinehart, B. C. (2010). Exploring conditions to enhance students/host family interaction abroad. Foreign Language Annals, 43 (1), 64-79.

Lafford, B. (1995). Getting into, through, and out of a survival situation. In B. F. Freed (Ed.) Second language acquisition in a study abroad context (pp. 97-122). Philadelphia, PA: John Benjamins. 
Lafford, B. (2004). The effect of context of learning on the use of communication strategies by learners of Spanish as a second language. Studies in Second Language Acquisition, 26 (2), 201-225.

Magnan, S. S. (1986). Assessing speaking proficiency in the undergraduate curriculum: Data from French. Foreign Language Annals, 19, 429-438.

Martin, J. R., \& Rose, D. (2003). Working with discourse: Meaning beyond the clause. New York, NY: Continuum.

Martinsen R. A., Baker, W., Dewey, D. P., Bown, J. (2010) Exploring diverse settings for language acquisition and use: Comparing study abroad, service learning abroad, and foreign language housing. Applied Linguistics. 20. 45-69

Milton, J., \& Meara, P. (1995). How periods abroad affect vocabulary growth in a foreign language. ITL Review of Applied Linguistics, 107-108, 1734.

Paige, R. M., Cohen, A. D., Kappler, B., Chi, J. C., \& Lassegard, J. P. (2002). Maximizing study abroad: A student's guide to strategies for language and culture learning and use. Twin City, MN: CARLA.

Pellegrino, V. A. (2005). Study abroad and second language use: Constructing the self. Cambridge, UK: Cambridge University Press.

Regan, V. (1995). The acquisition of sociolinguistic native speech norms: Effects of a year abroad on second language learners of French. In B. F. Freed (ed.). Second Language Acquisition in a Study Abroad Context. 245267. Philadelphia, PA: John Benjamins.

Regan, V. (1998). Sociolinguistics and language learning in a study abroad context.Frontiers: The Interdisciplinary Journal of Study Abroad, 4, 2. 61-90.

Regan, V. Howard, M., \& I. Lemée (2009). The acquisition of sociolinguistic competence in a study abroad context. Bristol: Multilingual Matters.

Ritchie, J., \& Lewis, J. (2003). Qualitative research practice: A guide for social science students and researchers. London: SAGE Publications Ltd.

Rivers, W. P. (1998). Is being there enough? The effects of homestay placements on language gain during study abroad. Foreign Language Annals, 31, 4. 492-500.

Segalowitz, N., \& Freed, B. F. (2004). Context, contact, and cognition in oral fluency acquisition: learning Spanish in at home and study abroad contexts. Studies in Second Language Acquisition, 26 (2), 173-199.

Schmidt-Rinehart, B. C., \& Knight, S. M. (2004). The homestay component of study abroad: Three perspectives. Foreign Language Annals. 37, no. 2. 254-262. 
Shively, R, L. (2010). From the virtual world to the real world: A model of pragmatics instruction for study abroad. Foreign Language Annals, 43 (1), 103-137.

Taguchi, N. (2008). Cognition, language contact, and the development of pragmatic comprehension in a study-abroad context. Language Learning, 58, 33-71.

Towell, R., Hawkins, R., \& Bazergui, N. (1996). The development of fluency in advanced learners of French. Applied Linguistics, 17 (1), 84-119.

Wilkinson, S. (1998a). On the nature of immersion during study abroad: Some participant perspectives. Frontier: The Interdisciplinary Journal of Study Abroad, 4, 121-138.

Wilkinson, S. (1998b). Study abroad from the participants' perspective: a challenge to common beliefs. Foreign Language Annals, 31 (1), 23-39.

Wilkinson, S. (2002). The omnipresent classroom during summer study abroad: American students in conversation with their French hosts. Modern Language Journal, 86 (2), 157-173. 


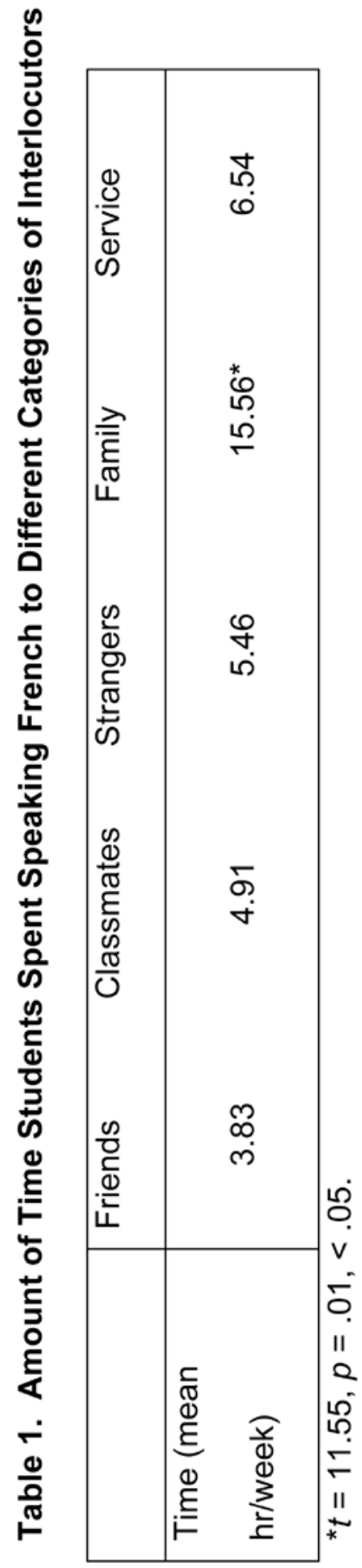




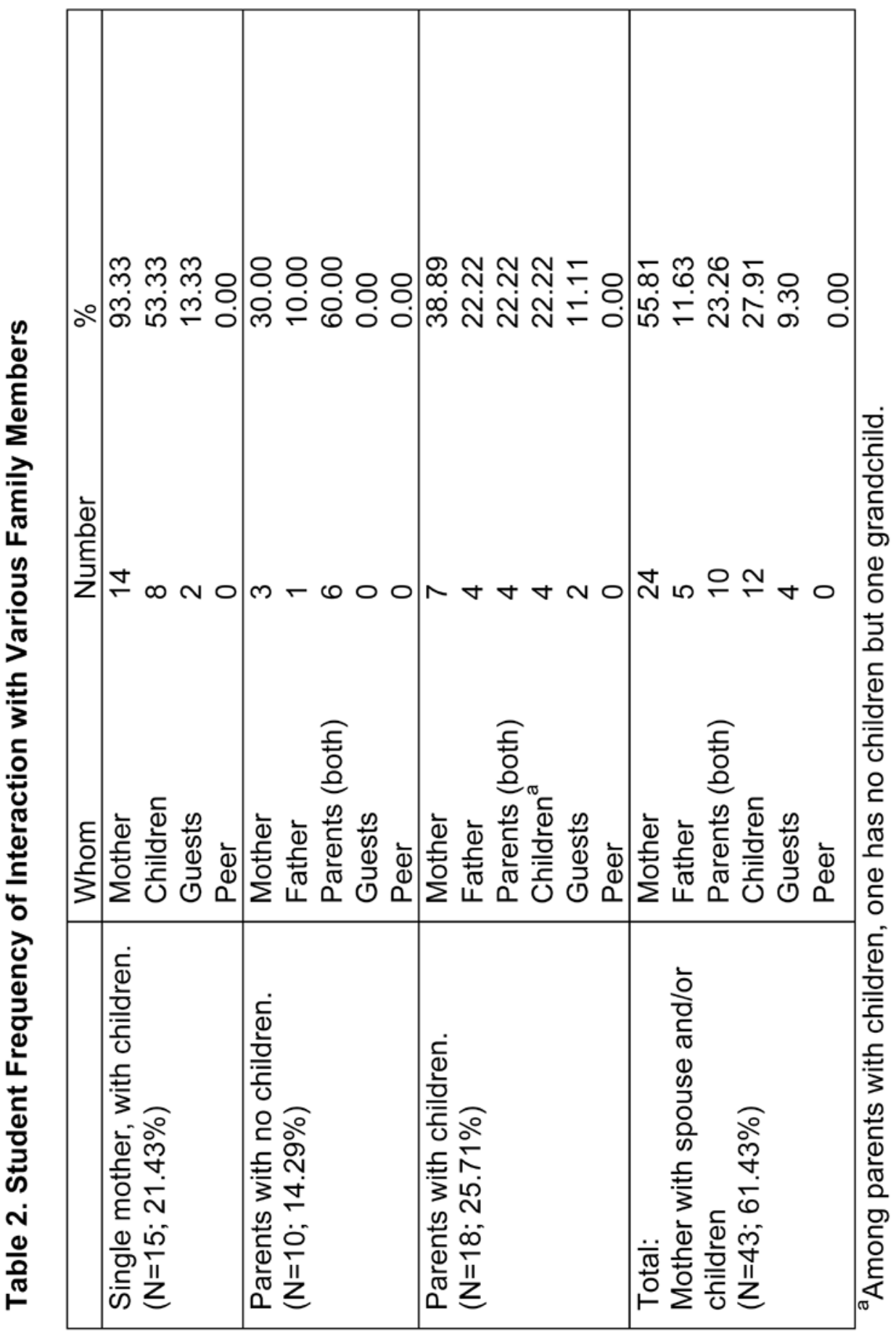




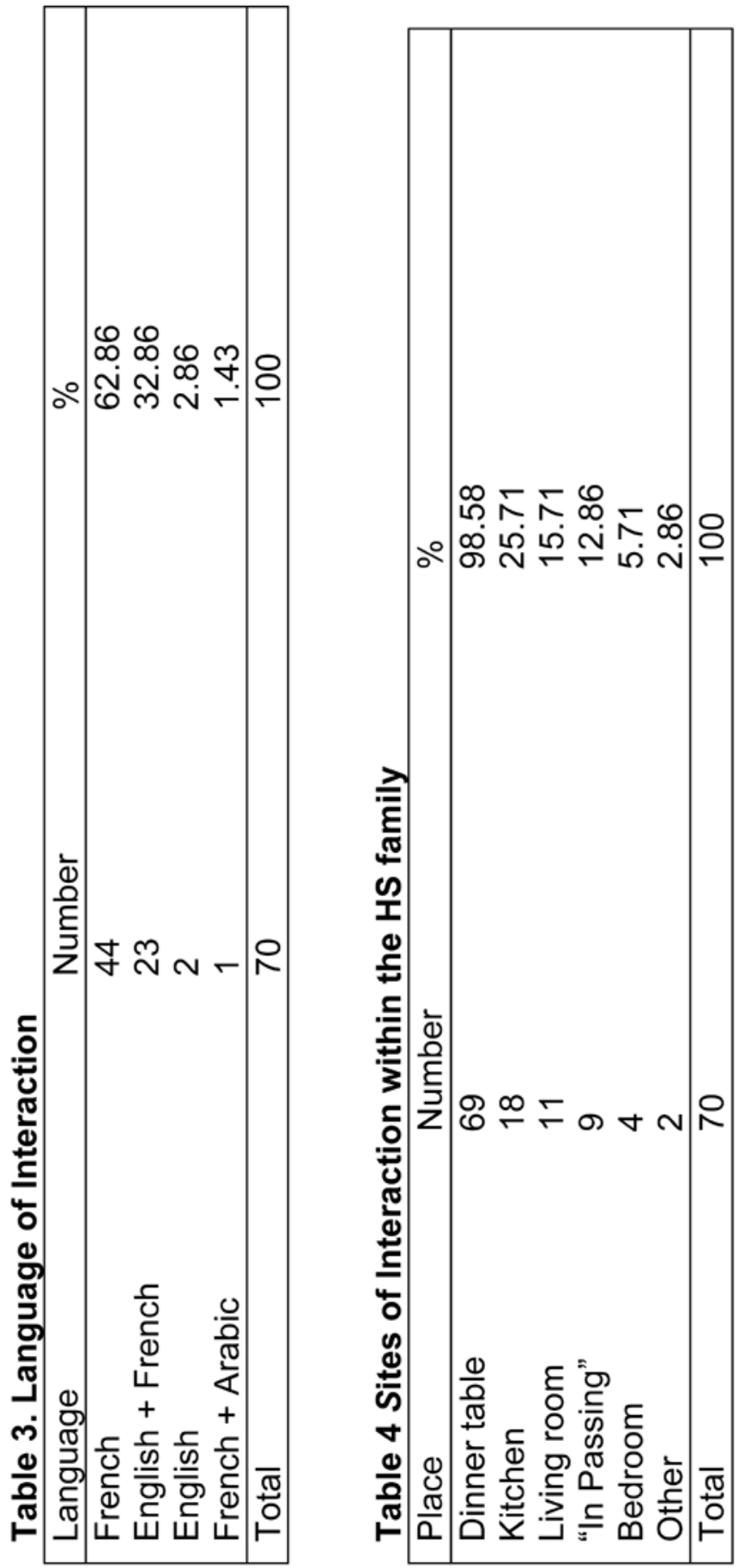




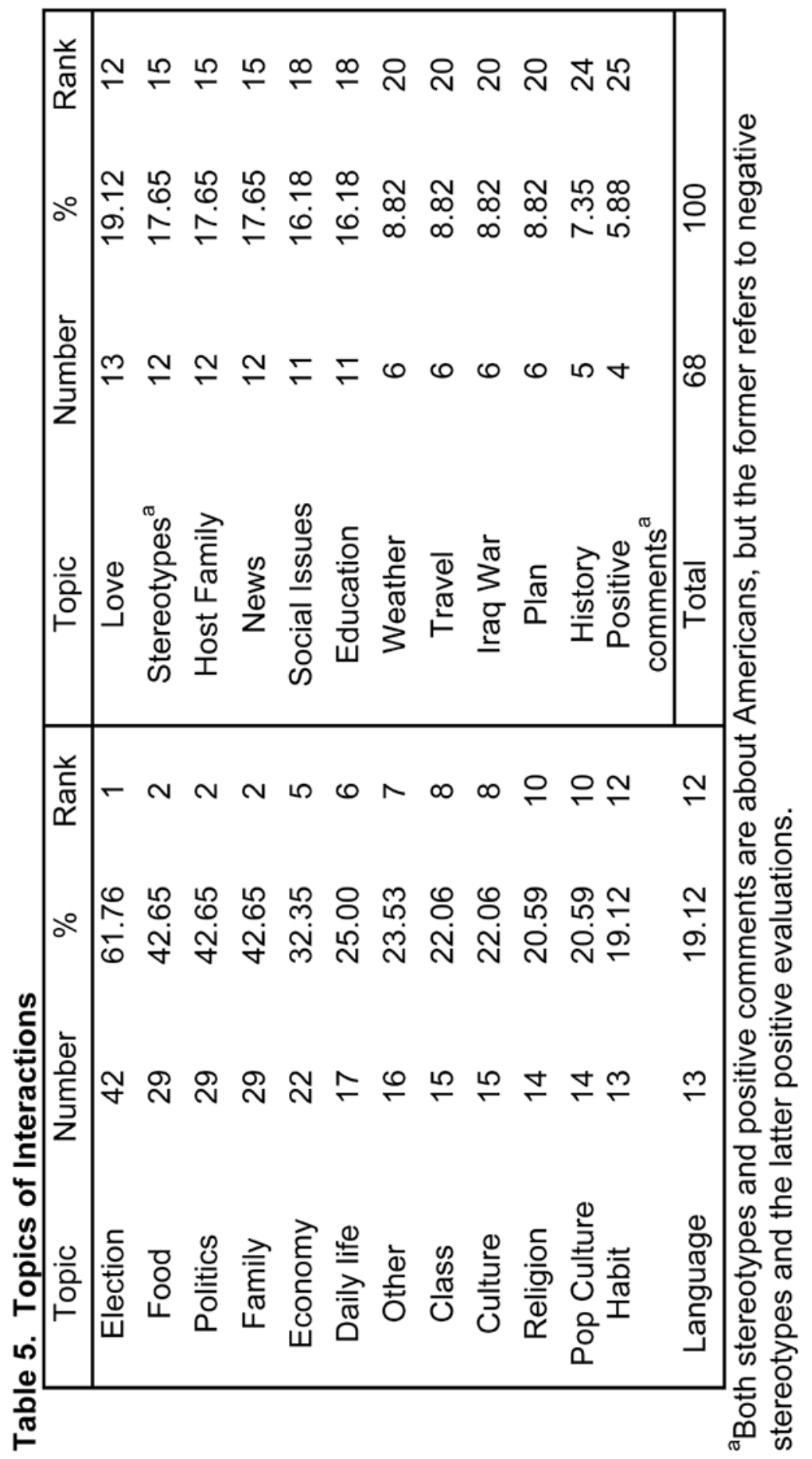




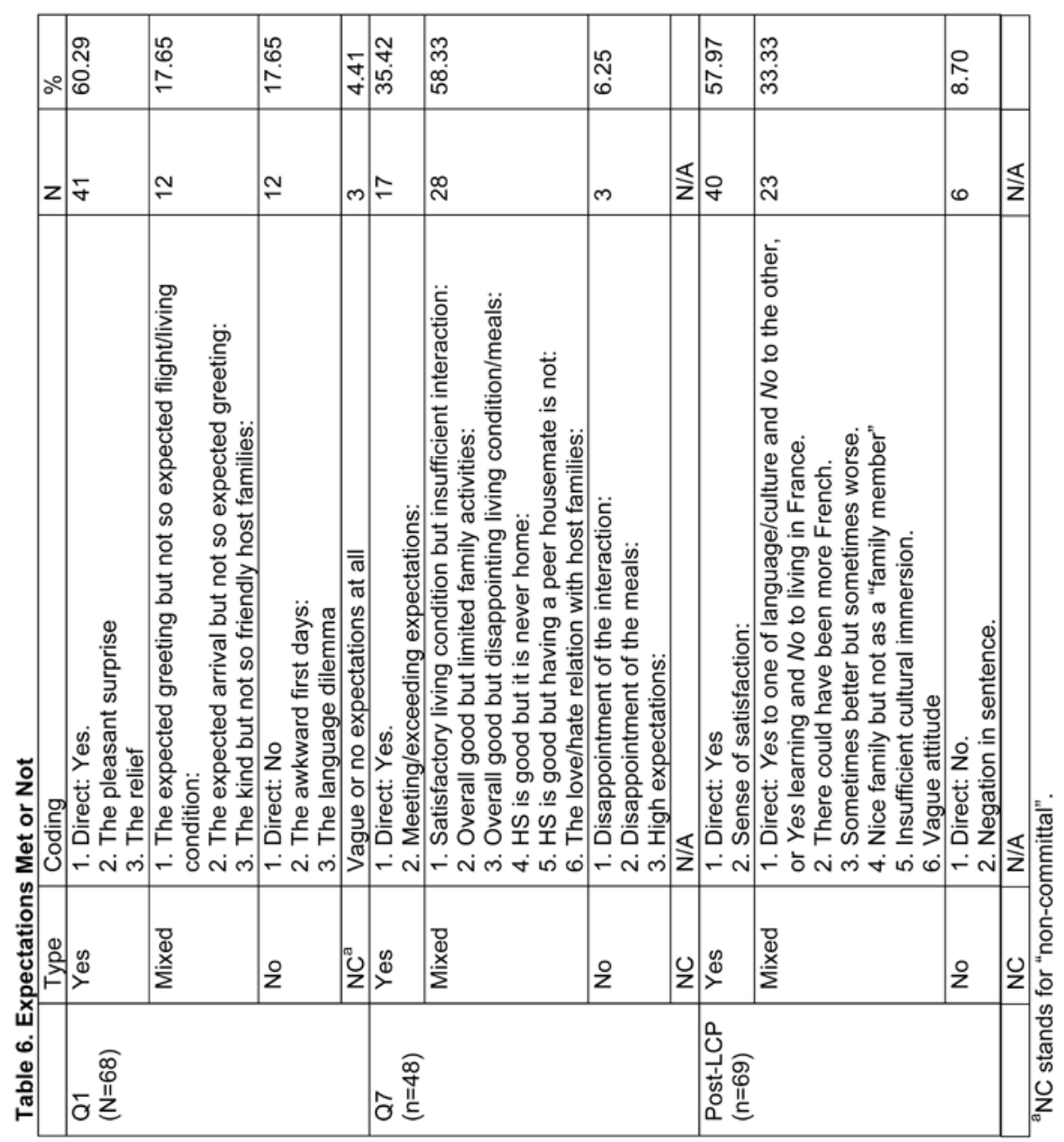




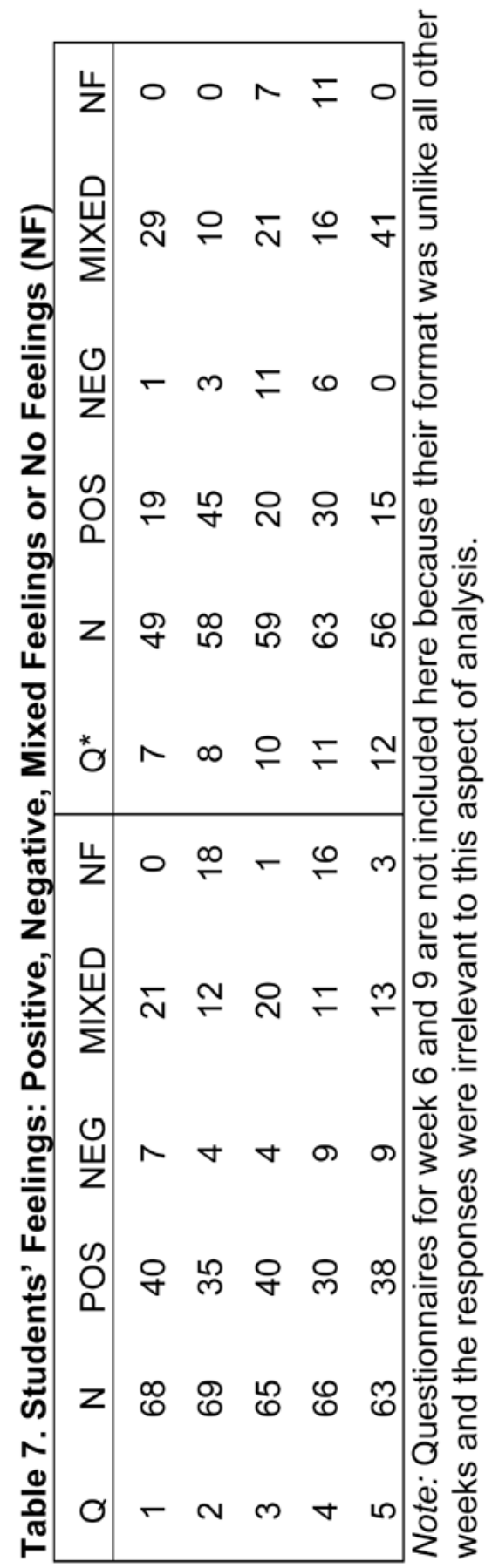




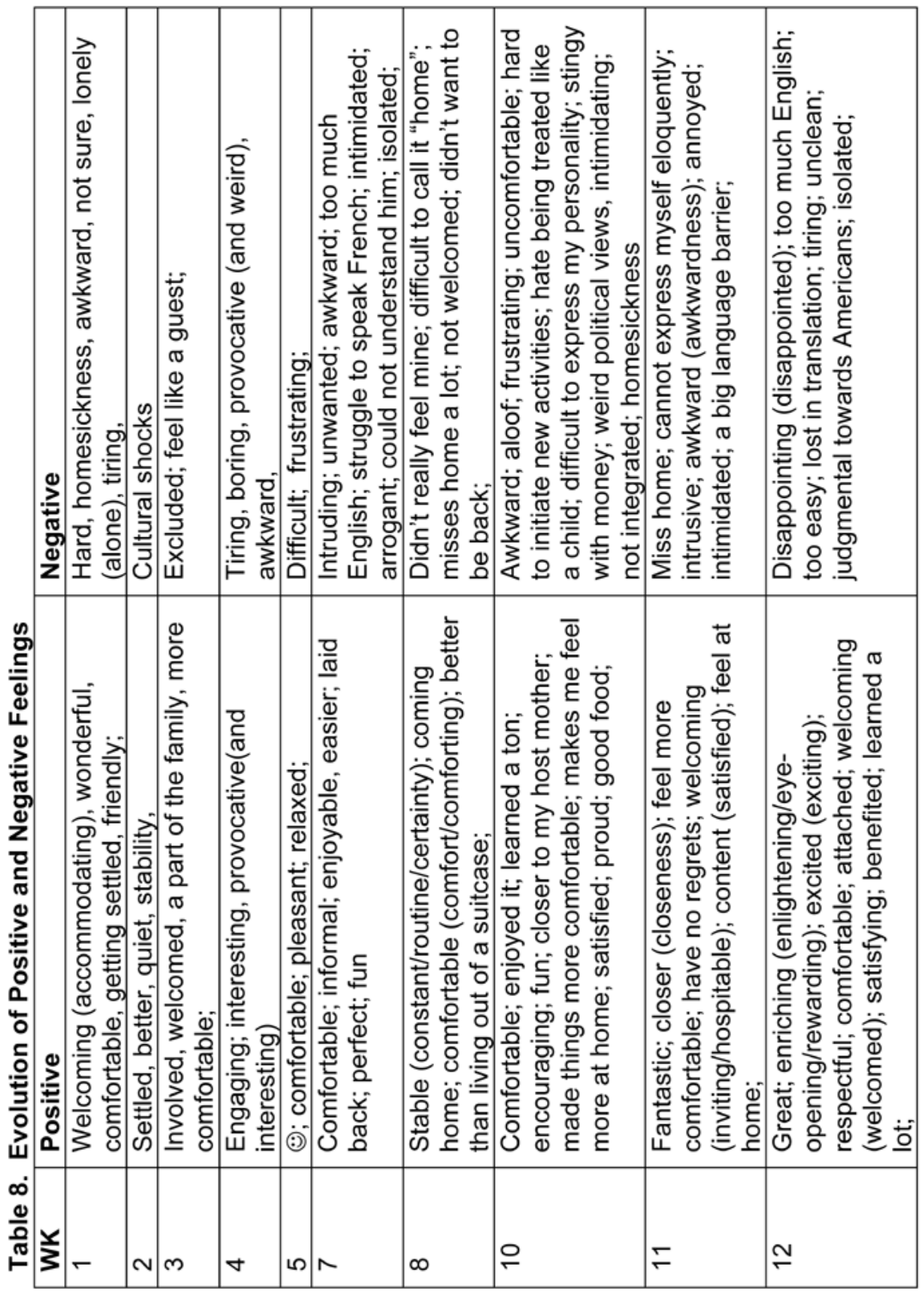


Figure 1. U-shaped curve for the evolution of expectations.

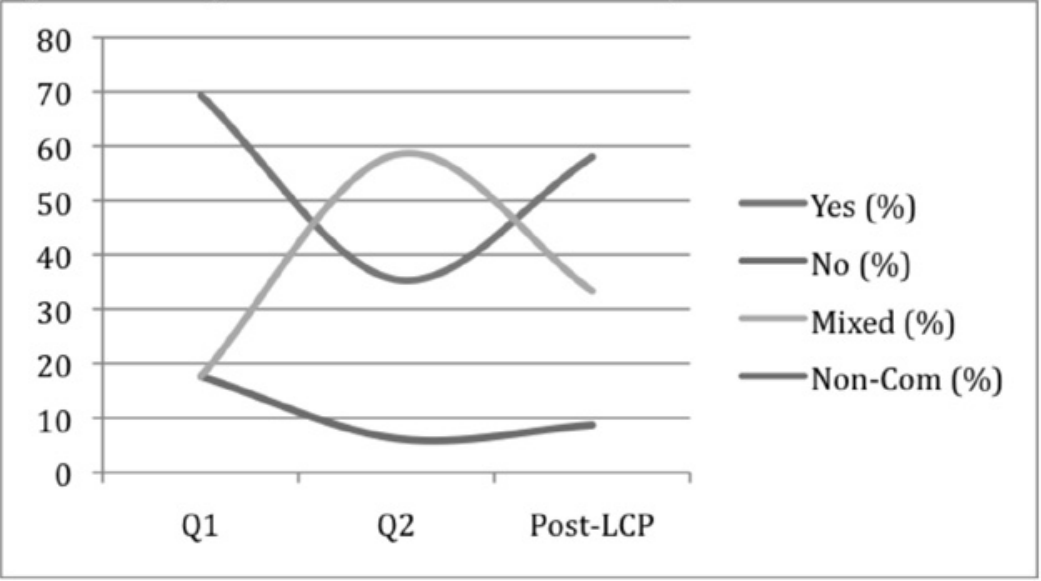

Figure 2. Evolution of feelings

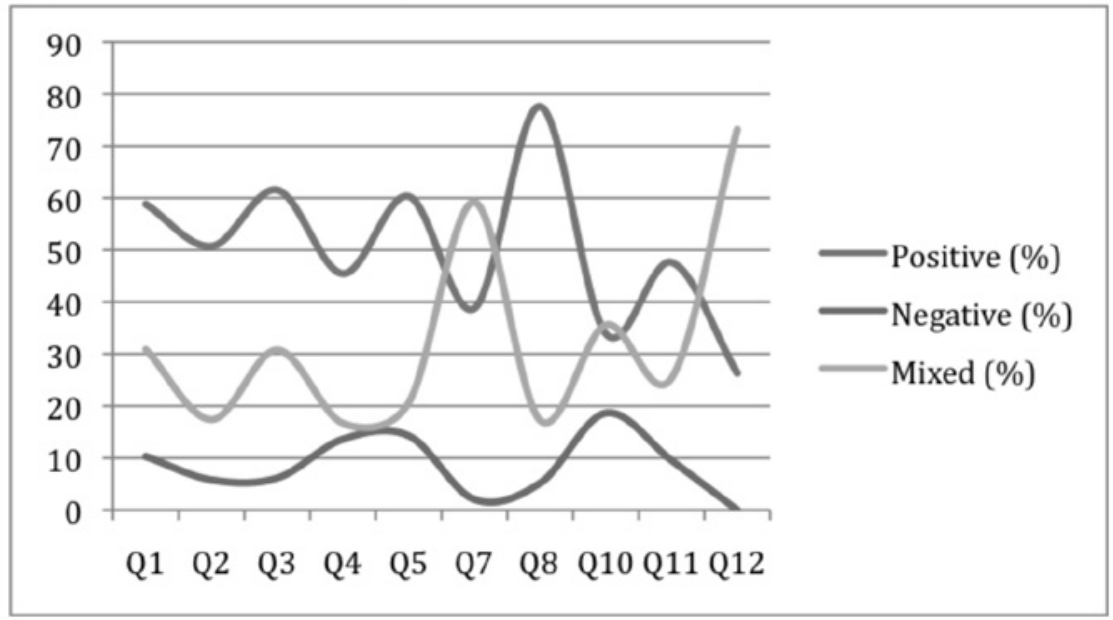

